\title{
Experimental study on separation of valuable refractory aggregate from investment casting ceramic shell waste
}

\author{
*Ji-gao Li', Yuan-cai Li' and Shi-ming Tan ${ }^{2}$ \\ 1. School of Materials Science and Engineering, Huazhong University of Science and Technology, Wuhan 430074, Hubei, China \\ 2. Hanchuan Shijin Technology Co., Ltd., Hanchuan 432300, Hubei, China
}

\begin{abstract}
In the present study, a processing technique for recycling investment casting ceramic shell waste was proposed to separate valuable refractory aggregate zircon sand. The microstructure and phase constituents of the shell waste and separation process were investigated. The results show that the characteristics of microstructure and phase constituents of the shell waste can meet the conditions for preferentially separating zircon sand, and zircon sand can be separated by gravity separation on a shaking table. The separated zircon sand has good shape and high purity, and can be used for the production of castings and other applications.
\end{abstract}

Key words: investment casting ceramic shell waste; zircon sand; magnetic separation; gravity separation

CLC numbers: TG221 ${ }^{+}$Document code: A Article ID: 1672-6421(2016)04-243-05

\begin{abstract}
A s a near-net shape forming process, investment casting finds more and more applications because of the increasing focus on the quality of new products ${ }^{[1-3]}$; therefore, the amount of shell waste produced is huge. As with the conventional casting process, the investment casting process will produce pollution and waste of resource materials if they are not properly disposed. A lot of attention has been paid to recycling the used sand in conventional casting, and some effective processes have been developed and applied, which, however, are not suitable for recycling investment casting shell waste. Compared with conventional casting, the shell waste has higher strength after shakeout because it experiences a more complex process during shell-making. To date, the complexity of recycling the waste inhibits the development of investment casting ${ }^{[4-7]}$. Thus, developing new approaches of recycling the investment casting ceramic shell waste is of great significance.

Extensive investigations on recycling the used shell from investment casting have been conducted by Zhao, et al ${ }^{[8-11]}$. The recycled materials were reused as the back sand for making new shells in investment casting, or
\end{abstract}

\footnotetext{
*Ji-gao Li
}

Male, born in May 1973; Ph.D. candidate. Research area: molding materials and new technology on materials forming.

E-mail: ljg9956@163.com

Received: 2016-01-24; Accepted: 2016-05-30 as refractory aggregates for preparing coatings in the production of iron castings. However, investigations revealed that most factories were reluctant to recycle the shell waste due to the complex recycling process, as well as the instable product quality, and consequently, the companies still disposed the used shell as waste. Because of China's shortage of resources, enhancing the enterprises' enthusiasm to reusing waste shell and developing new recycling processing techniques are inevitable and necessary.

The consumption of zircon sand for steel castings in China is enormous, and its supply mainly relies on imports because of resources exhaustion of it in China. Its price fluctuates greatly, even up to $22,000 \mathrm{CNY} /$ ton in recent years. Researchers at HUST suggested a new processing technique for recycling ceramic shell waste: the valuable refractory materials (such as zircon sand) are firstly separated from the waste, followed by comprehensively utilizing the remainders. By doing this, the total cost of recycling the waste may be reduced greatly because it can avoid costly zircon sand being simply discarded or used as ordinary materials. Not only can the recycled zircon sand be used as surface sand material, but also be processed into powder, serving as other products. Therefore, the feasibility of separating zircon sand from ceramic shell waste was studied in this work. 


\section{Experimental procedures}

\subsection{Materials}

Investigations on several precision casting factories in Hubei revealed that the shell layers used in investment casting among enterprises were different, depending on their product categories. Generally, the content of zircon sand in ceramic shell ranges about $8 \%-25 \%$. The material used in this research came from a precision casting company in Hubei province. This company is mainly engaged in the production of carbon steel castings, with an annual output of 400 tons. The shell waste was stored in an open environment, and disposed as garbage.

\subsection{Experimental design}

The microstructure of the shell waste was observed before separation experiments. Representative shell waste was selected from the shell waste heap and samples were cut with a saw blade for microstructure observation using optical microscopy and scanning electron microscopy (SEM). Also, some zircon sand was taken from the first sanded layer for phase constituent analysis. The phase constituent analysis was carried out on X-ray diffraction (XRD) apparatus.

Gravity separation method was used to separate zircon sand from the used shell. According to the analysis on the source of raw materials of the shell, zircon sand in the shell had a size range of 80-120 mesh. Considering the separation capacity of the shaking table, the particles supplied to the shaking table were determined in size range of 80-250 mesh. In order to determine the crushing process, different means were adopted to break the shell waste according to the particle size distribution. The flow chart of the separation process used in the present research is shown in Fig. 1. After manual sorting, the shell waste was fed into the crusher for crushing, and followed by drying and screening. Then zircon sand with size below 80 mesh was put on the shaking table for gravity separation. Manual sorting was designed to filter the complex shell waste and to make it relatively clean. Drying was used to adjust the moisture of the shell, to ensure that subsequent screening procedure can be carried out smoothly. The 6-s shaker was used for gravity separation. The parameters of the shaking table were adjusted to a clear borderline between the zircon sand and other abrasive particles on the shaking table which can be observed with the naked eyes. Separation times were determined according to the purity and recovery requirements. Two levels of magnetic separation were arranged during the gravity separation process to remove the iron impurities as much as possible. Finally, the contents of zircon and iron of the recovered zircon sand by gravity separation were evaluated.

\section{Results and discussion}

\subsection{Microstructure and phase constituents of shell waste}

Figure 2 shows the macrostructure of the used shell. It can be seen that the used shell still has an obvious layered structure.

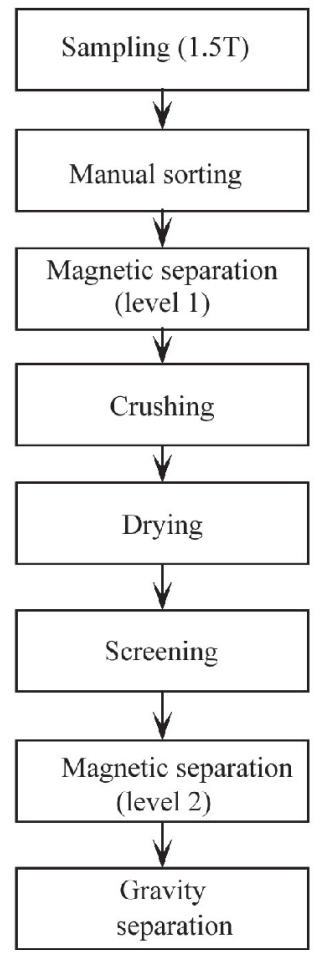

Fig. 1: Flow chart for separation process

In the figure, the iron and iron oxide layer is marked as A, the first sanded layer of zircon sand is marked as B, and the second sanded layer of zircon sand is marked as $\mathrm{C}$. The layer between A-B and B-C is refractory coatings. It can be seen that the sanded layer of zircon sand is not eroded by the hot metal, and zircon sand retains its original state. Figure 3 shows the microstructure of the used shell. In the figure, D is zircon sand in the sanded layer (80-120 mesh), and E is zircon sand in the coating layer ( $\sim 325$ mesh). There are a lot of pores and cracks between sand particles and between the sand particles and the coating in the shell waste, and zircon sand grains are not entirely surrounded by coating due to contraction of the coating layer. XRD patterns of the first sanding layer of zircon sand is shown in Fig. 4. It can be seen from Fig. 4 that only $\mathrm{ZrSiO}_{4}$ phase is detected. It implies that the chemical reaction did not happen in the zircon sand after firing and pouring.

The surface layer was not penetrated by the iron melt due to two factors. First, the zircon sand has high refractory qualities, and second, the thermal shock in the casting process reduces rapidly because of the large temperature gradient in the thin shell ${ }^{[12]}$. In this case, the zircon sand in the sanded layer keeps its original state. This is very favorable for recycling. As long as a reasonable separation process was adopted, the separated zircon sand in the sanded layer could be maximized. At the same time, thermal shock leads to the crack in the shell because different materials have different shrinking rates. Therefore, the zircon sand particles in the sanded layer are not surrounded by the coating wholly. All these factors are beneficial for separating the zircon sand particles from other substances. Based on the abovementioned reasons, the zircon sand in the two sanded layers could maintain its original phase. 


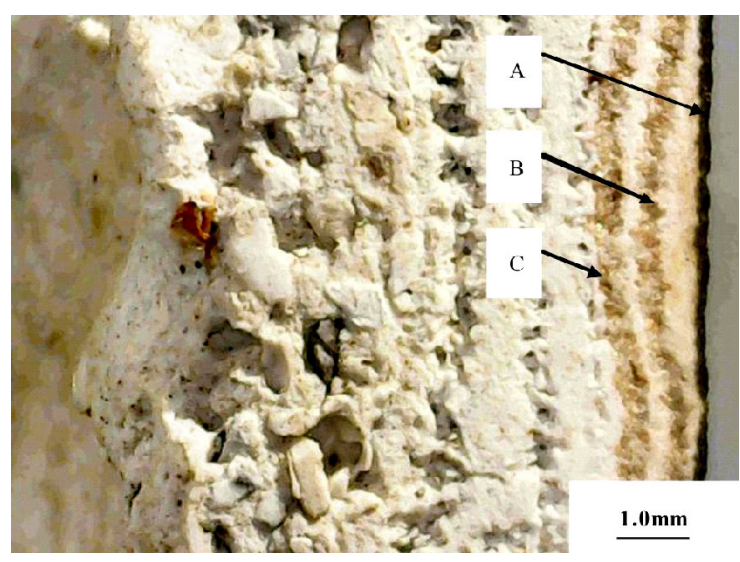

Fig. 2: Sectional drawing of shell waste (by portable digital microscope)

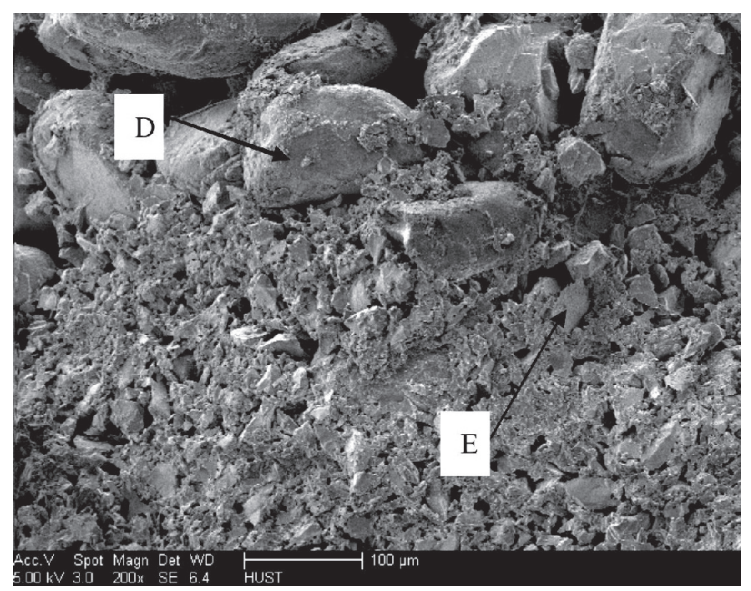

Fig. 3: Sectional drawing of shell waste (by SEM)

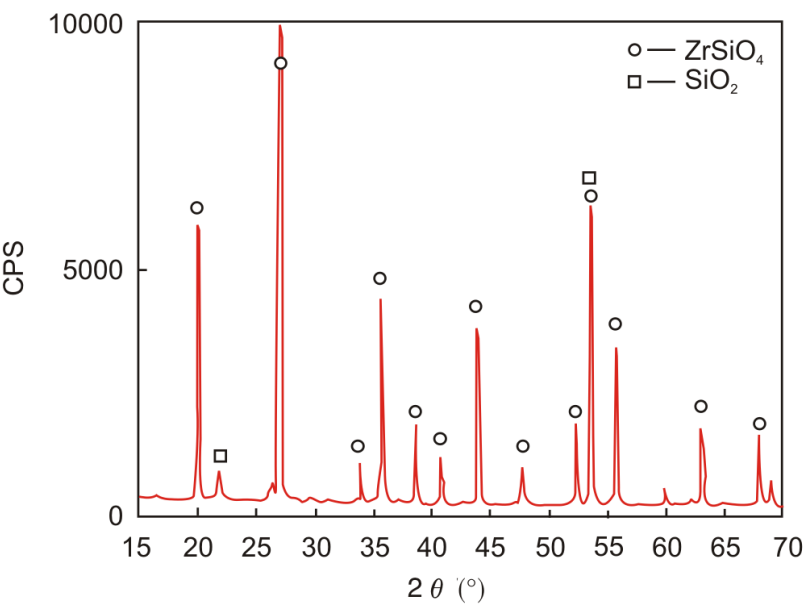

Fig. 4: XRD patterns of zircon sand in the first sanded layer

\subsection{Results of gravity separation}

\subsubsection{Crushing and sieving}

In the present research, a crushing process was used. The procedure is as follows: (1) breaking by a composite crusher, (2) milling by a ball mill for $3 \mathrm{~h}$, (3) screening by 80 mesh and 250 mesh sifters. The result showed that $94 \%$ of the separated zircon sand particles could pass the 80 mesh sifter, and $68 \%$ could pass the 250 mesh sifter.
Because only the particles within $80-250$ mesh can be fed to the shaking table for gravity separation, the proportions abovementioned are obviously low. This means that the sand particles have high fragility and the shell waste can be easily broken. Therefore, excessive crushing should be avoided when designing the crushing process. Roller crusher or rod mill is the preferred process, and a wet grinding method can also be considered.

\subsubsection{Partition on shaking table}

The final parameters for the shaking table were determined after repeated tests: inclination of $0.5^{\circ}$, water consumption of $15 \mathrm{~L} \cdot \mathrm{min}^{-1}$, stroke distance of $8 \mathrm{~mm}$, stroke per minute of 50 beats. As seen in Fig. 5, the shaking table area can be divided into three regions. In region $\mathrm{A}$, the uniform and transparent and round sand grains are clean, and it can be judged as zircon sand. In the region $\mathrm{B}$, there are some black impurities, and largegrained zircon sand, and mullite can be observed. In the region $\mathrm{C}$, the sand is white and block-like, so it can be judged as mullite. After a secondary separation of the particles in region $\mathrm{B}$, the zircon sand could be successfully separated.

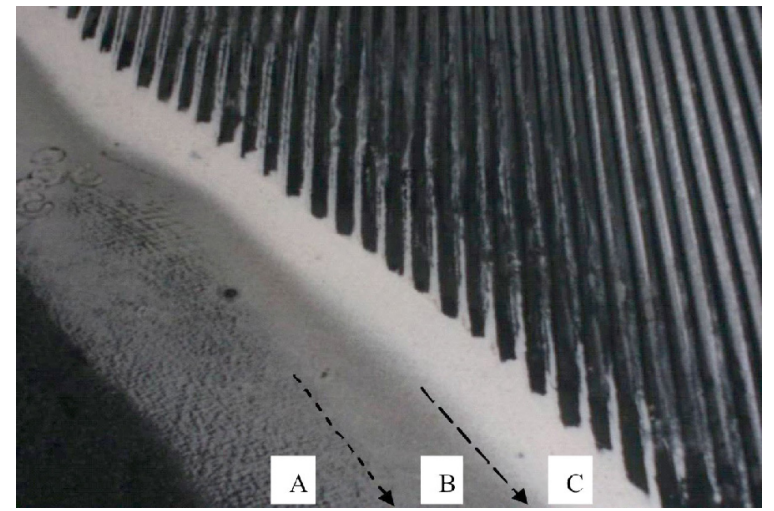

Fig. 5: Partition of separated particles in shaking table surface

Gravity separation is the process of separating different substances according to their different densities. The sand particles become loose and layered within the bed trench due to water flow and vibration. The layered sands are subjected to different water flow pressures and friction along the direction of motion. Because the upper hydraulic drive of light sand is greater than the bottom, most of the sand in this region is prone to move downward along the surface. At the bottom of the table, sand particles are directly driven by differential movement of the table and moved to the opposite drive end. The different densities and granularities of the sand grains lead to different motion directions, so sand particles from the sand tanks fan out along the diagonal lines. Therefore, the product discharges along the edge of the bed and in different regions. The required particles are finally extracted.

According to the theory of mineral processing, density ratio between different particles is the main criterion for a shaking table ${ }^{[13-14]}$. Density is the main factor influencing the difficult level of gravity separation which is often estimated by the value of coefficient $e$. The coefficient $e$ can be defined by the formula (1): 


$$
e=\frac{\delta_{2}-\Delta}{\delta_{1}-\Delta}
$$

where:

$\delta_{1}$-the density of light mineral

$\delta_{2}$-the density of heavy mineral

$\Delta$-the density of medium

In this study, zircon sand belongs to the heavy mineral and its density is about $3.8 \mathrm{~g}^{\circ} \mathrm{cm}^{-3}$, while the mullite sand belongs to the light mineral and its density is about $2.5 \mathrm{~g}^{\cdot} \mathrm{cm}^{-3}$. Water is the medium and its density is $1.0 \mathrm{~g}^{\cdot} \mathrm{cm}^{-3}$. Therefore, based on formula (1), the value of $e$ is 1.87 . According to Table 1, this value falls in the easy type for gravity separation. This is in conformity with the experiment result.

Table 1: Difficult level of gravity separation and relative lower limit of size

\begin{tabular}{ccc} 
Value of e & $\begin{array}{c}\text { Difficult level } \\
\text { of gravity } \\
\text { separation }\end{array}$ & $\begin{array}{c}\text { Lower limit of } \\
\text { particle size }(\mathrm{mm})\end{array}$ \\
\hline 5 & Very easy & $0.010-0.0005$ \\
$2.5-1.75$ & More easy & 0.019 \\
$1.75-1.5$ & Easy & $0.075-0.038$ \\
$1.5-1.25$ & Difficult & 0.5 \\
$<1.25$ & More difficult & $\begin{array}{c}\text { More than a few } \\
\text { millimeters }\end{array}$ \\
& Impossible &
\end{tabular}

It should be noted that, although density ratio is the main criterion considered in gravity separation process, many other factors such as the size and grain shape of the particles should not be neglected. In some cases, mica with flake shape directly determines the result of gravity separation. As with the same density, larger particles are prone to be promoted in the upper groove. This is the reason why the particles are coarser in region $\mathrm{B}$ than that in region A (Fig. 6). For region B, the difference in particle size is not significant. Zircon and mullite can be distinguished further using a shaking table.

\subsubsection{Test of separated sand}

The contents of $\mathrm{Zr}\left(\mathrm{ZrSiO}_{4}\right)$ and $\mathrm{Fe}_{2} \mathrm{O}_{3}$ in the sand in regions $\mathrm{A}$ and $\mathrm{B}$ were tested respectively after drying. The results show that $\mathrm{Zr}\left(\mathrm{ZrSiO}_{4}\right)$ content was over $95 \mathrm{wt} . \%$, and $\mathrm{Fe}_{2} \mathrm{O}_{3}$ content was below $0.3 \mathrm{wt} . \%$. For region $\mathrm{B}$, after further separation, $\mathrm{Zr}\left(\mathrm{ZrSiO}_{4}\right)$ content was more than $90 \mathrm{wt} . \%$, but iron content increased slightly. In addition, some sands were covered with a dark layer, and it can be selected by magnetic separation or cleaned by acid leaching

From the above morphology observation of the separated zircon sand, zircon can be restored to its original status, so the purity of the separated zircon sand can be relatively high. Zircon sands with different grades could be obtained by adjusting the area to gather zircon sand and the times of the separation process.

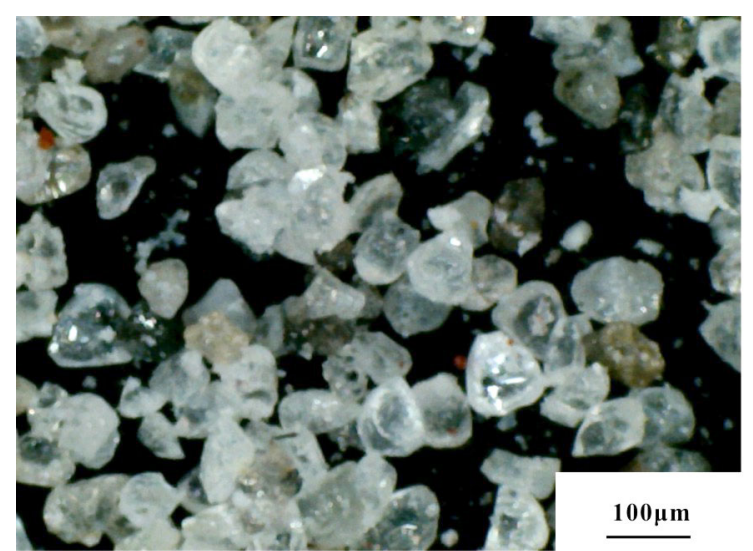

(a) Region $\mathrm{A}$

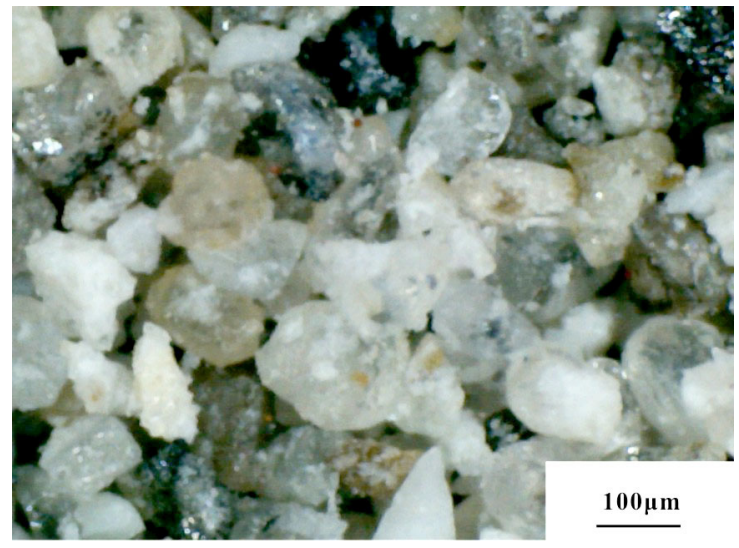

(b) Region B

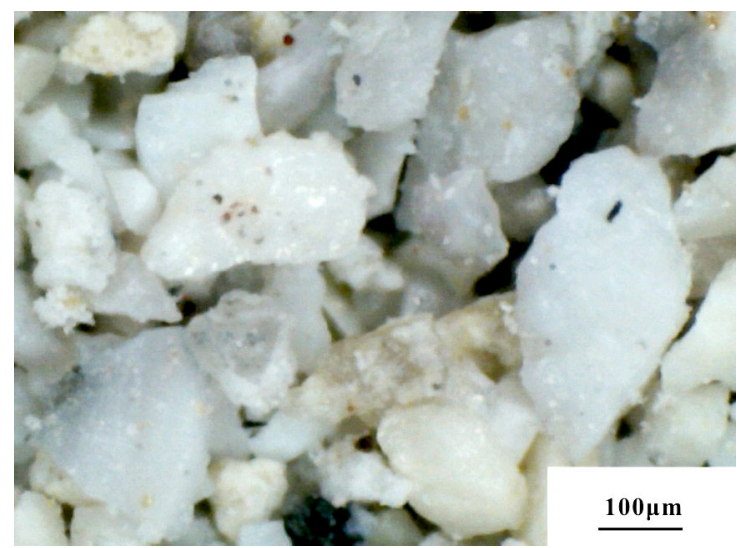

(c) Region C

Fig. 6: Characteristic of sand in different partitions

\section{Conclusions}

(1) The sanded layer of zircon sand is not eroded by the hot metal. Zircon sand in the layer is not surrounded wholly by coating. Chemical reaction does not seem to happen in the layer after firing and pouring, and the zircon sand retains its original state. Meanwhile, the shell waste can be easily broken. All these can be regarded as favorable conditions for preferentially separating valuable refractory materials..

(2) According to the gravity separation process described above, zircon sand can be separated successfully from the shell waste, and a clear borderline between the zircon sand and 
other particles on the shaking table can be easily identified. The process can be optimized further according to purity and recovery requirements.

(3) For the separated zircon sand, the shape is good, and $\mathrm{Zr}\left(\mathrm{ZrSiO}_{4}\right)$ content can be over $95 \mathrm{wt} . \%$. It can be used in the production of castings, and also in many other applications.

(4) Zircon sands with different grades could be obtained by adjusting the area gathering the zircon sand and the times of the separation process.

\section{References}

[1] Jones $S$ and Yuan C. Advances in shell moulding for investment casting. Journal of Materials Processing Technology, 2003, 135(2): 258-265.

[2] Tong Tianfu, Chen Bing, Jiang Buju, et al. Investment casting process. Beijing: China Machine Press, 1991: 1-16. (In Chinese)

[3] Pattnaik S, Karunakar D B, Jha P K, et al. Developments in investment casting process - a review. Journal of Materials Processing Technology, 2012, 212(11): 2332-2348.

[4] Tsai W T and Chou Y H. Government policies for encouraging industrial waste reuse and pollution prevention in Taiwan. Journal of Cleaner Production, 2004, 12(7): 725-736.

[5] Nunes K R A, Mahler C F, Valle R, et al. Evaluation of investments in recycling centres for construction and demolition wastes in Brazilian municipalities. Waste Management, 2007 27(11): 1531-1540.
[6] Lavee D, Regev $U$, Zemel A, et al. The effect of recycling price uncertainty on municipal waste management choices. Journal of Environmental Management, 2009, 90(11): 3599-3606.

[7] Zhao W, Leeftink R B, Rotter V S. Evaluation of the economic feasibility for the recycling of construction and demolition waste in China - The case of Chongqing. Resources, Conservation and Recycling, 2010, 54(6): 377-389.

[8] Zhao Hengyi. Study on reclamation and recycle of waste sodium silicate. Environmental Engineering, 2003, 21(6): 5658. (In Chinese)

[9] Zhao Hengyi. Study on reclamation and recycle of the ceramic shell waste in investment casting. In: Prodeedings of the 1st International Symposium on Nonferrous Alloys and Special Casting Technologies. Shanghai: China Foundry Association, 2003: 201-205. (In Chinese)

[10] Zhao Hengyi and Wang Jianming. Reclamation and recycle of Silica Sol mold shell molding waste. Special Casting \& Nonferrous Alloys, 2004(2): 50-51. (In Chinese)

[11] Zhao Hengyi. Analysis of ingredients and re-usage of investment casting mould scraps. Special Casting \& Nonferrous Alloys, 2005, 25(1): 52-54. (In Chinese)

[12] Li Yuancai. Formation technology of liquid metal materials. Beijing: Chemical Industry Press, 2007: 20-35. (In Chinese)

[13] Wang Xuyan. Handbook for the new technology and process inspection standard and process equipment calculation of mineral processing. Beijing: China Knowledge Press, 2005: 553-556. (In Chinese)

[14] Yu Jinwu and Li An. New process, new technology, new equipment and mandatory standard for modern mine. Beijing: Contemporary China Audio and Video Publishing House, 2010: 1364-1365. (In Chinese) 